\title{
ERRATUM
}

Jocelyne Letarte · Ecaterina Simion • Mai Miner •

Ken J. Kasha

\section{Arabinogalactans and arabinogalactan-proteins induce embryogenesis in wheat (Triticum aestivum L.) microspore culture}

Published online: 4 July 2006

(C) Springer-Verlag 2006

\section{Plant Cell Reports (2006) 24: 691-698}

In Material and methods, the subsections "Microspore induction culture" and "Plant differentiation and regeneration" contain errors. Please find the correct sentences below.

Microspore induction culture

The induction medium, MMS4, (Kasha et al. 2003a, b) was modified MS medium (Murashige and Skoog 1962) containing $2 \mathrm{mgl}^{-1} \mathrm{PAA}, 0.5 \mathrm{mgl}^{-1}$ kinetin, $90 \mathrm{gl}^{-1}$ maltose, $355 \mathrm{mgl}^{-1} \mathrm{U} 2.5$ amino acid mix (Comeau et al. 1992), and $975 \mathrm{mgl}^{-1}$ glutamine.

Plant differentiation and regeneration

Once ELS reached a size of about $2 \mathrm{~mm}$, they were transferred onto differentiation medium: MMS5 (Kasha et al. 2003a, b) containing $0.5 \mathrm{mgl}^{-1}$ PAA, $0.2 \mathrm{mgl}^{-1}$ kinetin, $0.5 \mathrm{mgl}^{-1} \mathrm{GA}_{3}, 30 \mathrm{gl}^{-1}$ maltose, $355 \mathrm{mgl}^{-1}$ Sigma U2.5 amino acid mix, $10 \mu \mathrm{M} \mathrm{CuSO}_{4}$ at $22^{\circ} \mathrm{C}$ during a $16 \mathrm{~h} \mathrm{light}$ period.

The online version of the original article can be found at http://dx.doi.org/ 10.1007/s00299-005-0013-5

J. Letarte · E. Simion · M. Miner · K. J. Kasha $(\bowtie)$

Department of Plant Agriculture, University of Guelph,

Ontario, Canada, N1G 2W1

e-mail: kkasha@uoguelph.ca

Tel.: +519-824-4120

Fax: $+519-763-8933$ 